\title{
Rebonds: Structural Affordances, Negotiation, and Creation *
}

\author{
Ben Duinker
}

NOTE: The examples for the (text-only) PDF version of this item are available online at: https://www.mtosmt.org/issues/mto.21.27.4/mto.21.27.4.duinker.php

KEYWORDS: performance and analysis, rhythm, tempo, structure, percussion

\begin{abstract}
This paper presents a comparative recording analysis of the seminal work for solo percussion Rebonds (Iannis Xenakis, 1989), in order to demonstrate how performances of a musical work can reveal-or even create-aspects of musical structure that score-centered analysis cannot illuminate. In doing so I engage with the following questions. What does a pluralistic, dynamic conception of structure look like for Rebonds? How do interpretive decisions recast performers as agents of musical structure? When performances diverge from the score in the omission of notes, the softening of accents, the insertion of dramatic tempo changes, or the altering of entire passages, do conventions that arise out of those performance practices become part of the structural fabric of the work? Are these conventions thus part of the Rebonds "text"?
\end{abstract}

DOI: $10.30535 / \mathrm{mto} .27 .4 .0$

Received December 2020

Volume 27, Number 4, November 2021

Copyright $\odot 2021$ Society for Music Theory

[1.1] I learned the solo percussion work Rebonds (Iannis Xenakis, 1987-89) under the concurrent tutelage of two professors who came from different schools of interpretation. After initial apprehension towards this approach to learning the work, I noticed that the commentary I received from each teacher always complemented, or built upon, the advice of the other: there was rarely any contradiction. Had I simply gotten lucky in my choice of teachers? Indeed, I had, but upon further reflection, I concluded that my luck in this event had more to do with Rebonds itself. This is a work that affords a wide latitude of interpretive and analytical perspectives. It was as though the tutelage I received had been tapped from a collective pool of Rebonds knowledge, and with each lesson, I acquired greater access to this pool. My interpretive evolution of Rebonds never felt linear; each new experience expanded the realm of available possibilities. This non-linearity assumed greater significance when I began to investigate Rebonds through an analytical lens. I questioned the utility of a score-centered analytical approach. How could such an approach - without recourse to performances-account for the interpretive multiplicity this work affords? And how can that multiplicity be accounted for in the very structural fabric of the work? 
[1.2] This article presents a comparative recording analysis of Rebonds, based on the assumption that performances of a musical work can reveal, or even generate, aspects of musical structure that score-centered analysis cannot easily illuminate. I analyze the audio of ten commercially recorded interpretations of Rebonds - listed in Example 1-across multiple musical parameters. ${ }^{(1)}$ The first two of these, tempo and pitch, can be assessed objectively through computational methods. The next two, accent articulation and grouping structure, are subjectively studied by ear. The final section addresses score fidelity at particular moments in the work. Through the comparative study of tempo, pitch, accent, grouping, and score fidelity, I reflect on the following two questions. What does a pluralistic, dynamic conception of structure look like for this work? How do variegated interpretive decisions reinforce or confound this conception? Using performances as an entry point to the analysis of a work encourages the situation of that work as a living, evolving object.

[1.3] While such an analytical approach is appropriate for any musical work that is notated and performed, it is especially relevant for Xenakis's music, for two reasons. The first is historical. Aesthetically true to his place as a composer working in post-war, avant-garde Europe, Xenakis's musical voice draws little from established paradigms in Western art music. His compositional language relies less on pitch- or form-centric conventions, and more on parameters such as timbre, texture, and rhythm. James Harley surmises that this musical language is partially responsible for the "lack of attention [toward Xenakis's music] in the analytical community" (2004, ix). What attention Xenakis has received in the analytical community has normally been both work-specific and compositionally oriented, asking implicit questions like: what are the materials and processes inherent in this work? and how is the work put together? Often, Xenakis's background as an architect and mathematician is referenced. ${ }^{(2)}$ While no doubt insightful, this approach sidesteps the second reason that using performances is relevant: Xenakis's music is, put simply, immensely difficult to learn and perform. ${ }^{(3)}$

[1.4] In her introduction to Performing Xenakis (2010), Sharon Kanach characterizes the act of interpreting Xenakis's music in terms of "negotiation" - a negotiation through which performers develop solutions to the challenges presented to them in the score. ${ }^{(4)}$ These challenges regularly involve issues of accuracy and faithfulness to the score, and it is thus in this sphere that Kanach's "negotiations" take place. Sylvio Gualda - the premiering performer and dedicatee of Rebondsalso characterizes the process of preparing for performance as a negotiation in that "any reading of a musical text implies an interpretation, which, in essence, is an attempt to minimize the distance between the performer and the composer, between the instrument and the score" (159). Traversing the distance between Xenakis and performers of his work embodies something of a "Xenakian performance practice" and appeals to an analytical approach that foregrounds interpretations as agents in actualizing the structural affordances of his compositions.

[1.5] I borrow this concept of "structural affordances" from Nicholas Cook, who mentions it in his monograph Beyond the Score (2013). ${ }^{(5)}$ Cook briefly explores the idea of "performers . . .creat[ing] meaning within the structural affordances of compositions, meaning that cannot itself be encompassed within a purely structural description" (68). What are these structural affordances? I interpret this idea as departing from a singular, monolithic conception of structure, that is, the structure of a musical work. While one of Cook's agendas in Beyond the Score is to advocate that analysis be "weaned from [its] fixation with structure" (2), I propose that a re-characterization of musical structure can also be productive, especially in light of musical works that have little to gain from established formal paradigms. This means, in a sense, that I am following the work of Daphne Leong, whose recent book Performing Knowledge (2019) explores, among other things, "how the composer harnesses instrumental and physical limitations to create structure" (2016, [9]). In the case of Rebonds, I aim to demonstrate how it is the performers who harness instrumental and physical limitations to create structure by responding to a score that exposes these limitations. Put this way, I understand musical structure as more of an umbrella term to describe the performer's interpretation of a score, and by extension, the apprehension of this interpretation through sound. (6) Structure can thus manifest across an entire performance but also at the hyperlocal level, as a product of seemingly minor, or even inconsequential performative actions such as the omission of single notes or (in the case of Rebonds) the decision to hold four mallets instead of two. I am thus adopting a similar "reverse engineering" approach following Caroline Palmer (1996); working 
backwards from performances to recover sources of the expression and manifestation of structure. (7)

\section{Xenakis and Rebonds}

[2.1] Iannis Xenakis left behind a lengthy œuvre of works and composed in a style that evolved throughout his career. ${ }^{(8)}$ Several through lines permeate his output, including a homage to ancient Greek culture and folklore and frequent engagement with scientific and mathematic principles and processes. ${ }^{(9)}$ Rebonds was composed between 1987-89, toward the end of Xenakis's life, and constitutes one of his last works to feature percussion. Despite its relatively young age as a musical work, Rebonds has become one of the most oft-performed solo percussion works worldwide, a canonized classic amid a fast-growing body of solo-percussion literature. Numerous performance competitions and graduate school auditions use it as required repertoire. ${ }^{(10)}$ Taken in the context of Rebonds, then, percussionist and pedagogue Steven Schick's words are apt: "it is not an exaggeration to say that for many contemporary percussionists learning how to play has meant learning how to play the music of Xenakis"' $(2010,200)$.

[2.2] Set in two movements entitled " $\mathrm{A}$ " and " $\mathrm{B}$ " (which can be performed in either order), Rebonds is scored for a selection of skinned and wooden instruments; seven drums in Rebonds $A$, and five drums and five woods (usually, but not always, conventional wood blocks) in Rebonds B (see score legend and general instrument setup diagrams in Example 2). ${ }^{(11)}$ The drums cover a wide pitch and timbral span, ranging from concert bass drums to bongos. Selection of the wooden instruments is left to the discretion of the performer, although these five woods should be timbrally consistent and cover a wide pitch range. Each movement employs a process-driven form. Rebonds $A$ begins with a simple two-note motive that undergoes a slow and steady process of intensification, or filling-in. Rebonds $B$ begins with a polyphonic groove - in that two distinct musical voices are present-where a pulsing ostinato overlays a four-note cyclical pattern. Of the processes that act on these initial states in each movement, Schick writes that "both movements detail a progression from a simple and categorical exposition of material through a presentation that is increasingly fractured and alienated from its original form" $(2006,205)$. The fracturing effect on the opening materials in Rebonds $A$ involves the gradual densification of both rhythmic and pitch space, such that the opening two-note motive (see Example 3) becomes partially buried beneath the accumulating material. But it is always there, occasionally surfacing and ultimately prevailing in a new, fragmented form, after the densification process has imploded and laid bare the musical surface.

[2.3] Rebonds B undergoes a more discrete type of process: repeated attacks on the stability of the opening groove render it increasingly volatile. At first, the groove is able to "rebound" following these attacks, which come in the form of intense bursts of thirty-second notes and tremolo (rolled) passages. But the damage is done, so to speak: first the ordering of the cyclical groove becomes altered, and ultimately the two-stroke "ruff" (see Example 15), previously the sole property of the high bongo, cascades across all five drums. Rebonds B's moment of truth occurs in $\mathrm{m}$. 65, the last instance where any semblance of the opening groove is felt. After this point, an unsteady pairing of tremolo and rhythmic passages prevails over all ten instruments, ultimately dissolving into a chorus of tremolos that represent a reconciliation: a gravitation outward in pitch space toward the coexistence of low and high pitch and of skinned and wooded timbre.

\section{Tempo: Appearances Can be Deceiving}

[3.1] Software-aided tempo measurements can be used to analyze various aspects of performance practice, expressivity, and musical structure. Eric Clarke notes that solo keyboard recordings appeal to studies of timing because the "percussive character of the instrument makes it an effective way to study rhythmic skills, and makes accurate timing analysis from sound files possible" $(2004,78) .{ }^{(12)}$ The percussive character of the instruments used in Rebonds makes it similarly appealing for software-aided timing analysis. Below I investigate several excerpts from both movements of Rebonds, measuring performance tempi across the ten recordings. For each 
excerpt, I begin by observing the general approach to tempo taken by the performers, treating these observations as the starting points for analysis. It is only then that I explore rationalizing these observations with recourse to the musical material presented in the score.

[3.2] The marked tempi for Rebonds $A$ and $B$ seem easy to effectuate at each movement's opening but grow increasingly difficult thereafter. The score for Rebonds $A$ indicates an approximate tempo of $40 \mathrm{bpm}$ (beats per minute). There are no other tempo markers; while the performer might choose a tempo different from $40 \mathrm{bpm}$, there are no indicators that the chosen tempo should fluctuate throughout the movement. I measured performance tempi across five measure-long excerpts in the movement: m. 1, m. 19, m. 34, m. 41, and m. 49. ${ }^{(13)}$ These measures-each detailed in Example 3were chosen because they represent unique stages in the movement's formal process of densification while also posing specific challenges to the performer. In m. 1, a high-low gesture between the high bongo and bass drum is stated. This gesture is present throughout the movement, but is reshaped, filled in, and occasionally obscured. By m. 19, the vertical aspect (register) has been saturated. By m. 34, the rhythmic surface has grown increasingly dense, and double-accented notes have begun to occur. The repeated-note figures present in $\mathrm{m} .41$ evoke a groove-like passage, while the near-impossible rhythmic density found in $\mathrm{m} .49$ foreshadows an imminent breakdown of musical material. These five measures each present challenges concerning performance tempo. The sparseness of $\mathrm{m}$. 1 might invite a performance tempo that simply cannot be sustained through the dense texture of $\mathrm{m}$. 49. The passages in $\mathrm{m} .19$ and $\mathrm{m} .34$ allow space for performers to inject temporal fluidity through rubato performance. The temptation to perform these two measures (and the surrounding material) at higher tempi might be motivated by ergonomics; careful consideration to drum placement can make these passages quite idiomatic to perform. ${ }^{(14)}$ And finally, the groove-based syncopation displayed in $\mathrm{m} .41$ could invite the performer to settle into a particular comfortable performance tempo that is unique to this section.

[3.3] With an approximate tempo marking at the beginning, and highly variegated rhythmic material throughout Rebonds A, it might come as no surprise that interpretations of this movement diverge widely in their pacing. Example 4 documents performance tempi from each recording for the five passages described above. A similar tempo contour emerges for many of the performances: a relatively slower opening, followed by an increase in tempo, and concluding either with a return to slower tempi or the maintenance of a faster one. ${ }^{(15)}$ Nine of the ten recordings follow this general trajectory; only Ying-Hsueh Chen's performance does not. Chen is also the only performer who begins the movement noticeably faster than $40 \mathrm{bpm}$; most of the other performances begin below the indicated tempo, with Hans-Kristian Kjos Sørensen's being the slowest at 27 bpm. This discrepancy is substantial: Sørensen begins his performance at approximately two-thirds the indicated tempo. Stopping short of ascribing intent to Sørensen's performance, we might surmise that he-and others-are making conscious decisions to begin below the marked tempo by some aesthetic or narrative motivation, perhaps in order to create space to use an acceleration of tempo as a dramatic tool later. But if that were the case, we would expect to see more variety in the tempo contours of Example 4. Another explanation might be that Sørensen begins slowly in order to maintain tempo through the increasing complexity of ensuing material, but his dramatic acceleration to $37 \mathrm{bpm}$ across the first 19 measures would appear to dispel this theory.

[3.4] The preceding discussion reveals three general tendencies across the performances: they normally begin slower than the indicated tempo, they tend to accelerate soon thereafter, and they then either maintain a higher tempo or decelerate in the final stages of the movement. ${ }^{(16)}$ Given this consistency in tempo approach, we are wont to ask whether aspects of the notated score invite it-aspects that may not be apparent if the score were studied apart from its interpretations. The statement in $\mathrm{m} .1$ is declamatory in its rhythm and register, elemental in its simplicity, and incessant in its repetition. It serves as a call-sign for the whole movement. A number of recordings studied here-especially Sørensen's - seem to highlight the primacy and importance of this opening gesture by spending increased time on it, not rushing it. In the opening of Rebonds $A$, new musical developments occur one after the other: the filling in of horizontal space (at the sixteenthnote level) is complete by $\mathrm{m}$. 5, the first polyrhythm occurs in $\mathrm{m} .6$, thirty-second notes begin to appear in $\mathrm{m} .7$, and sixty-fourth notes at $\mathrm{m}$. 17. Concurrent with these new states of rhythmic density is an ongoing increase in their frequency after being introduced, such that by $\mathrm{m}$. 20-where 
an eighth-note attack punctuates a hitherto constant rhythmic surface-the presentation of musical material in this movement is complete. This material is spoon fed to the performer, who in turn spoon feeds it to the listener. It would seem that one means for achieving this would involve a deliberately slow opening tempo followed by ongoing (though not necessarily constant) accelerando through the first 20 measures.

[3.5] This assessment of slower performance tempi at the movement's opening is thus rooted in notions of practicality: a slower tempo enables the listener to better comprehend what is being added to the texture. A similar sense of practicality can help explain slower tempi taken at m. 49. This passage is extremely difficult to perform accurately, especially at $40 \mathrm{bpm}$. (We see in Example 4 that all ten performers take the passage below the marked tempo.) But it would be presumptuous to end the discussion here, on the notion that the difficulty of this passage is solely responsible for the slower tempi. In four of the recordings, tempo changes of less than $1 \mathrm{bpm}$ were observed between m. 41 and m. 49. As I note elsewhere (Duinker 2013), mm. 49-50 form something of a developmental climax in Rebonds A; no further saturation and build-up occur beyond this point. On the one hand, a steep and/or sudden drop in tempo might sever any cohesion with the section around m. 41. Schick's recording loses the most tempo, dropping approximately $7 \mathrm{bpm}$ between $\mathrm{m}$. 41 and $\mathrm{m}$. 49. This precipitous drop reflects the sudden proliferation of polyrhythmic figures in $\mathrm{m}$. 49: seven, compared to an average of just over one per measure in the passage that spans $\mathrm{mm}$. 4148. The heightened prevalence of polyrhythms in m. 49 means that it is $40 \%$ denser than $\mathrm{m} .48$ (when counting total note attacks), and 78\% denser than $\mathrm{m} .47$. This rapid and massive increase in density is reflected in Schick's performance: his abrupt deceleration functions akin to how the CPU in my computer slows down when too many programs are running simultaneously (a depressingly common occurrence). Such a connotation may read more negatively than is fair. In a sense, Schick's dramatic tempo drop highlights the structural importance of m. 49: a culmination of multiple simultaneous processes of musical development-a moment of "maximum impact," to quote Schick himself $(2010,201) .{ }^{(17)}$

[3.6] On the other hand, a constant performance tempo between the sections characterized by $\mathrm{m} .41$ and m. 49 coheres the development that leads to this climax. Christoph Sietzen loses no tempo at all between these measures (in fact, he even gains a bit of speed according to my measurements). As Example 4 details, his tempi across Rebonds $A$ are among the most constant of any performance studied here. By adopting this approach, Sietzen's interpretation reflects the notion of a smooth, rather constant sense of development and densification in this movement, even if we know this not to always be the case. In these foregoing discussions of $\mathrm{m}$. 1 and $\mathrm{m}$. 49, I do not mean to stress the value of one interpretation over the other; the narrative merit of each is tangible, and together give rise to multiple conceptions of structure.

[3.7] Rebonds $B$ opens with an indicated tempo of approximately $60 \mathrm{bpm}$, again inviting a degree of interpretive latitude. Example 5 charts the opening performance tempo for the ten recordings; while no performance begins at a tempo slower than 60 , most are quite close, but Chen's tempo is nearly $50 \%$ higher. ${ }^{(18)}$ This observed trend to perform this opening faster than the marked tempo, while not statistically significant due to the small sample of recordings, is - based on my experience with this work - indicative of a wider performance practice. Depending on the disposition of instruments, the opening Rebonds $B$ is quite idiomatic to perform (especially if the two-stroke ruff patterns are "cheated" as per the below discussion on performance fidelity). The pulsing of the high bongo, usually played with the right hand, calls upon a familiar motor skill for most percussionists, developed through playing time on hi-hat or ride cymbal at the drum kit. The cyclical pattern played on the lower drums is just that-cyclical-so the bodily motion required to play this line is predictable and falls into its own comfortable rhythm. Furthermore, this opening texture remains consistent for quite some time, meaning the performer is not burdened with navigating an ensuing densification as they are in Rebonds $A$. These comforts free the performer from being preoccupied with minute matters of interpretation, enabling them to inject a shade of vitality into their performance that comes, in part, from tempi slightly higher than $60 \mathrm{bpm}$.

[3.8] The performance tempi taken at the opening of Rebonds $B$ range from $62 \mathrm{bpm}$ (Isao Nakamura) to nearly $90 \mathrm{bpm}$ (Chen). The mean tempo falls just below $70 \mathrm{bpm}$, and closer to $65 \mathrm{bpm}$ when 
Chen's outlying tempo is discounted. As can be seen in the example, most of the chosen tempi are within the 60-70 bpm range with two visible outliers: Roland Auzet and Chen. These higher tempi impact how pulse is conveyed and perceived in performance. Chen's and Auzet's performancesand to a lesser extent also Schick's - have the potential to impress upon the listener a quarter-note tactus, while the slower performances convey an eighth note tactus. Justin London (2012) cites several perceptual studies that collectively reveal a preference for beat perception (as embodied through tapping experiments) at around $100 \mathrm{bpm} .{ }^{(19)}$ For interpretations of Rebonds $B$ that correspond closely to the indicated tempo of $60 \mathrm{bpm}$, perception of the pulse at the eighth-note level seems quite valid, given its tempo of $120 \mathrm{bpm}$. For the faster performances mentioned above, eighth-note pulses materialize at higher tempi: 140 for Schick, 154 for Auzet, and 178 for Chen. In these instances, it seems more plausible that a quarter-note pulse would be preferred.

[3.9] Tempo decisions taken at the movement's outset also bear consequence on later moments in Rebonds B, where faithful interpretation of the score becomes increasingly complicated, even at 60 $\mathrm{bpm}$. For now, however, I focus on two spots where it is entirely within the performer's controlregardless of tempo-to maintain a steady tempo. As in Rebonds $A$, there are no indications to alter the performance tempo, but performers nonetheless often do. In the passages documented in Example 6, the performer is required to play tremolo passages on the woods and drums, respectively. Independent of what type of tremolo might be used (there are several available to the adept percussionist), these passages are easily navigable at any of the tempi taken in the recordings. Why then, do many performers drastically alter the tempo in these sections, with some even adding fermatas? (See Example 6 for recordings of several approaches.) It is worth noting here that the contemporary percussion performance community does not exhibit consensus on rubato practices. ${ }^{(20)}$

[3.10] I propose that by inserting rubato, momentary slower tempi, and fermatas in these passages, performers (such as those heard in the audio embedded in Example 6) illustrate the thematic contrast between the rhythmic stability of the pulsing texture that dominates the movement's first 64 measures and the tremolo-fueled fragmentation of the movement's remaining 22 measures. On the one hand, this contrast characterizes the entire movement as tension-laden; the stability of the pulse figure is finally usurped by, and yields to, the rhythmically void tremolo texture. On the other hand, the stability of the pulse figure has, for some time, been under attack, and the repose brought on by this soft tremolo is a welcome return to stability. Indeed, this measure is also the first time the performer is confronted with a dynamic below forte. Interpreted in this light, such an extreme clashing of sound worlds imbues m. 65 with an outsized role in Rebonds B's form. If m. 65 constitutes a point of textural intersection between pulse and tremolo, then $\mathrm{m}$. 74 embodies a point of timbral intersection between skins and woods. It is here that they are first heard in concert, blended rather than juxtaposed. In a similar vein, then, m. 74 invites an injection of space by the performer, even though one is not explicitly called for in the score.

\section{Accent: To Play or Not to Play?}

[4.1] Musical accents necessitate a relativity between events that are "marked for consciousness" (Cooper and Meyer 1960,8) and their unaccented surroundings. Lerdahl and Jackendoff (1983) distinguish between metric, structural, and phenomenal accents. The following observations will mainly concern phenomenal accents, since notions of metric and structural accents are of little use in Rebonds. ${ }^{(21)}$ This is partly because the measures one sees in the score were added by the publisher (Xenakis's manuscript and sketches contain none), primarily as an aid for the performer. More importantly, while the material of each movement does evoke a sense of isochronous pulse, any sort of patterned organization above the level of the pulse is absent. ${ }^{(22)}$ Example 7 again presents the opening measure of Rebonds A. While the initial accented attacks on the high bongo furnish a sense of periodicity to which listeners can entrain a steady pulse, there is nothing here that strongly suggests a $4 / 4$ meter as dictated by the barlines. While the initial accented bongo attacks might sound like downbeats, the accent pattern quickly mutates in the fourth grouping of the first measure, and the addition of a third attack to the rhythmic gestalts thereafter ultimately discards a strong sense of consistent meter in this opening. 
[4.2] Rebonds does, however, feature an abundance of phenomenal accents-those that are explicitly notated for the performer to effectuate. Two levels of accents are marked in each movement of Rebonds, denoted by single and double accent symbols. ${ }^{(23)}$ In Rebonds $A$ these accents permeate the movement's opening material at a rate of approximately one accent per quarter note of material, or four per measure. As double accents emerge in $\mathrm{m} .23$ and become regular fixtures by $\mathrm{m}$. 40, these appear at an approximate frequency of one per half note of material, or two per measure. While these accents do not follow a consistent metric placement, they do, in a sense, form stratified textural layers, especially in mm. 40-50. Example 8 again shows m. 41, a representative measure from this section, where the double accents can be seen as anchoring an underlying stratum upon which the more frequent and audibly syncopated single accents operate.

[4.3] However compelling this reading of accent stratification may be, none of the performances analyzed thoroughly distinguish between these accent types. (Johannes Fischer's performance, excerpted with Example 8, represents one of the most distinctive differentiations between accent types and even his distinction is subtle.) On the one hand, diligent and consistent distinction between accent types is quite difficult to maintain, especially considering the rhythmic density of the passage shown in Example 8. On the other hand, such a widespread lack of accent distinction in these performances begs the question of the accents' structural significance: is my reading of their stratification relevant if performances typically do not create this structure? Is a sense of rhythmic stratification achievable without the double accents sounding distinct? Since many of the double-accented notes fall on quarter-note onbeats, and almost always on lower-pitched drums (relative to their immediate rhythmic surroundings), a sense of textural stratification is already built into the passage, even if performers do not explicitly differentiate between accent types. But this stratification is not realized through accents alone-only with an understanding that relative accent strengths dissolve in performance, and by observing their frequency and orchestration across the seven drum pitches do we appreciate here their role in textural stratification.

[4.4] The foregoing discussion encapsulates the nature of accents in $\mathrm{mm}$. 40-50 but does not rationalize the numerous other passages in Rebonds $A$ where accents are typically underperformed, thus failing to become "marked for consciousness" amid their unaccented surroundings. A common trajectory in accent interpretation seems to emerge across these ten recordings. Accents are dutifully interpreted in the rhythmically sparse opening of Rebonds $A$, but they become increasingly less marked as the movement progresses and densifies. To be sure, some of these performances adhere to accents more faithfully than others, but nearly all of them run into trouble at the dense passage in mm. 49-50 (excerpted in Example 9). Could it be that this passage is simply too difficult to perform as written? Sørensen's interpretation of this passage is one of the most faithful toward accent production among the ten recordings, but is also one of the slowest. By contrast, Pedro Carneiro's interpretation-which takes m. 49 the fastest of the ten recordingslargely ignores the accents printed in the score. These observations suggest that performers are forced to make a compromise here: one of either tempo or accents must be sacrificed in the service of the other. But again, this does not account for the other performances that are nearly as slow as Sørensen's with an avoidance of accents like Carneiro's. It seems, then, that accents and tempo are simply two parameters in Rebonds $A$ that are highly nuanced beyond their manifestations in the score, and as such, their relationship to structure can only be fully understood through assessments of performances.

[4.5] To a certain extent, accent consistency in these performances can be rationalized in a physiological sense. Repertoire for percussion setup involves a particular issue regarding accent: each drum or percussion instrument will respond differently to the same stroke (in both force and striking implement). In Rebonds $A$, Xenakis calls upon a variety of timbres in his assigned instrumentation of two bongos, three tom toms, and two bass drums. ${ }^{(24)}$ While these drums offer a wide pitch spectrum - consistent with the composer's wishes - their variegated construction yields a vast timbral palette. Bongos normally use drumheads made of animal hide pulled very tight over the drum's frame and are unskinned on the bottom. By contrast, tom toms and bass drums usually use synthetic heads tuned somewhat looser, and are double headed. This contrast is then exacerbated by the limitation of the performer using only one type of stick or mallet (each type coming with specific advantages and disadvantages with respect to sound production and 
ergonomics). In light of these practicalities, each drum will respond differently to an accented strike, and thus accents performed with the same stroke type on different drums will be unequal. Percussionists know this, and often compensate to smooth out dynamics and accent production. But in difficult, texturally dense repertoire like Rebonds, such an approach is not always viable. As a consequence, performances of this work will often elicit a collection of different accent strengths that relate to a consistent method of accent notation. This means that theorizing accent as a consistent structural aspect makes little sense here. Instead, treating it as a highly variegated parameter, actualized in many different ways through performance, investigates its structural role more appropriately.

\section{Pitch: Instrument Selection and Tuning}

[5.1] A drum's pitch range varies according to the diameter of its head (skin), whether it is singleor double-headed (skins over both the top and bottom of the drum), and what type of material the head is made from. Pitch in Rebonds - insofar as it is a component of structure-thus arises from instrument selection and tuning. In this sense, the score is remarkably indeterminate: by orchestrating the score for specific drums - bass drum, tom tom, bongo, etc. - Xenakis in effect determined an approximate acceptable pitch range for each movement. He also specified that the drums and woods used in Rebonds B occupy a "very wide [pitch] range" (1989). But drums such as tom toms vary widely according to size, and each drum itself can be tuned across quite a wide pitch range. Any investigation of pitch, then, must begin by considering the instrument selection and tuning of each performance. For space reasons, I limit the following discussion to tuning in Rebonds A.

[5.2] Among the drums called for in this piece, tom toms provide the most space for tuning variance. Rebonds $A$, for example, calls for (in ascending order of pitch) two bass drums, three tom toms, and two bongos. While tuning bass drums to different pitches is certainly possible, their low pitch usually means that timbral distinctions are easier to detect between different tuningspitches for concert bass drums rarely stray above C2 or D2. Bongos, on the other hand, are rarely tuned lower than C4 (middle C), because their sound quality and playability become compromised as their heads become looser. Furthermore, bongo heads can usually not be tightened any further than around F4 or G4, meaning the two pitches produced by the standard pair of bongos occupy a very small range. Between the upper edge of the bass drum range and the lower edge of the bongo range, then, this leaves nearly two octaves of space within which the three toms of Rebonds $A$ can reside. Example 10 details the approximate tunings used in each performance. ${ }^{(25)}$ Some tuning schemes involve widely and relatively evenly spaced pitches, particularly those used by Carneiro, Ferrière, Fischer, Sietzen, and Schick. Other schemes tend to cluster in the lower pitch space, such as those used by Auzet, Sørensen, and Nakamura. Finally, Chen and Kuniko Kato use schemes that induce large pitch gaps among the three toms; notable is the gap of a tenth between the low and middle toms heard in Kato's tuning scheme.

[5.3] How does drum tuning relate to structural analysis? Since percussion repertoire largely lacks access to the pitch structures that govern most music for other instruments, aspects of pitch contour and stratification are foregrounded. But given the varied tuning possibilities, this contour is not gleanable from the score alone. Example 11 places this notion in relief by transcribing $\mathrm{m}$. 30, first as it appears in the score, then as it is heard through the performances of Kato, Carneiro, and Auzet. What appears as a rather gently sloping pitch contour in the score is quickly revealed to be anything but, when the measure is modelled after each performance with respect to drum tuning. The single-staff notation of the score is thus reproduced in grand staves to account for the wide pitch range in these performances. Carneiro's tuning and instrument choices mean that his rendition of this passage produces three identifiable strata here: one through his upper bongos, another through his highest two tom toms, and a third through his remaining low drums. By contrast, Auzet and Kato's pitch layout involves large gaps. In the case of Auzet's tunings, any time the bongo drums interact with the tom toms in a rhythmic figure, the huge pitch gap between these instrument groups in his performance becomes foregrounded. This pitch orientation creates an issue of markedness then; by virtue of being so drastically separated from the rest of the drums by 
pitch, the two bongos assume a near-constant state of being "marked for consciousness." Kato's tunings present yet a different context: since her four highest drums are tuned very close in pitch (two are nearly identical), strings of rhythms where only these drums are used (such as at the end of this excerpt) are almost flatlined with respect to contour. Where Auzet's bongos stood out from the composite texture, Kato's bass drums and lowest tom tom do the same; in this passage in particular they seem (and indeed sound) isolated and buried in the dense texture created by the four highest drums.

\section{Phrase and Grouping in a Continuous Texture}

[6.1] The forms of Rebonds $A$ and $B$ - as they appear in the score-are fairly straightforward. Of the formal development in Rebonds $A$, for example, Schick writes that "it's simple" (2006, 209). He posits a large-scale formal plan for Rebonds $A$ that divides the movement into six sections (Schick calls these phases) of varying lengths, each of which are named according to their functional or rhetorical properties. ${ }^{(26)}$ But he stops short of ascribing any sort of precision in this sectionalization, writing that "interdependence among adjacent phases tends to obscure the boundaries [of formal units]" $(2006,211)$. Schick's assessment is accurate, but when the musical surface of this movement is closely scrutinized, subtle aspects of phrase and grouping emerge. Many of these are best described from a perceptual standpoint, for which a consultation of recordings is again invaluable.

[6.2] In order to situate notions of phrase and grouping in Rebonds A, I consult Anabel Maler's theory of phrase in post-tonal music (2018). Building on existing theories of phrase that were formulated for tonal repertoires, Maler generalizes post-tonal phrases as involving multiple musical items forming a coherent unit, articulated from other such units. ${ }^{(27)}$ From here she moves to the realm of in-time perception, outlining three factors that influence how phrase is perceived by listeners. Salient parameters are marked items that "emerge as important in making determinations about formal constituents" (55). Object categorization involves the process of listeners categorizing information they hear. And prospection / retrospection refers to the real-time intake and retention of information that informs future expectations. The listener constructs phrases, in other words, by grouping salient objects in a temporal boundary defined by marked events and the expectation of closure achieved by future marked events. How can Maler's theory be applied to Rebonds? First, it is important to distinguish that the idea of goal-directed motion upon which many theories of phrase are predicated is not easy to concretely identify in this work. Furthermore, segmentation markers - which would inform grouping structure-are equally difficult to identify. The score thus provides scant information with which an analysis might infer grouping or phrase structure. But I hesitate to abandon concepts of directed motion and grouping/segmentation for Rebonds, and thus look to recorded performances of the work to identify their presence.

[6.3] In both of the following passages in Rebonds $A$, the performer's use of accent, dynamics, and drum tuning affect grouping and phrase structure. In mm. 32-36 (excerpted in Example 12), single accents and short polyrhythmic bursts punctuate an otherwise near-continuous stream of rhythms at the sixteenth note or smaller subdivision. Without any clear segmentation of the rhythmic surface, it may seem most prudent to interpret this passage (and its surrounding material) as continuous. Indeed, some recordings support this interpretation. Carneiro's traversal of this passage is remarkably fluid, aided by the fact that he downplays the accents in the score. As Examples 10 and 11 can attest, his tunings are quite evenly spaced across the drums, meaning his movement across the setup is more amenable to producing a monophonic pitch contour-where the pitches are all heard as forming a single musical line-rather than a stratified texture. His interpretation of this passage thus impresses a continuous, wave-like motion, one that crests periodically but does not imply a strong sense of grouping or phrase.

[6.4] But on the other hand, by using drum tuning and dynamics, performers can organize this passage into salient groups that are characterized by the polyrhythms and accents. Sietzen frequently adds dynamic inflections not printed in the score, pronounces the accents quite strongly, and the timbre of his chosen instruments delineates them from one another. Notable here is the sound of his bongos. Sietzen is using sticks (as opposed to mallets), and his bongos sound as 
though they have plastic (and not the more standard rawhide) heads. This means that their timbre is quite distinct from the lower drums, enabling Sietzen to use them as structural markers if he so desires. (By contrast, he risks letting these drums stand out whenever they are played, thus compromising the fluidity of other passages where the bongos are not meant to be a distinctive sound event.) Though I stop short of proposing a grouping of this passage based on Sietzen's interpretation of it, my discussion of it here is meant to show how subtle distinctions of accent, pitch, timbre, and dynamics can imbue the musical surface with group- and segmentation-like characteristics. In effect, Sietzen's performance decisions give the listener salient parameters with which the process of object categorization might occur.

[6.5] Maler's third component, prospection / retrospection, is what transforms groups into phrases; it situates these groups in the temporal domain. In order to explore this idea more closely, I turn to mm. 40-45 of Rebonds A. As Example 13 demonstrates, the material here presents in two-part groups-boxed in the example. The first part usually begins with a double accent and is monorhythmic, featuring repeated attacks on various drums. The second part is rhythmically denser and contains polyrhythms. Measure 41 serves as a representative sample of this structure. While no two-part group in mm. 40-45 is identical with any other, their similarities are sufficient to impart a strong sense of half-note grouping. But these are groups, not phrases; at least, not yet, until a performer finds means to activate a directionality within them. Sørensen's performance achieves this through use of dynamics. He quite often crescendos through the polyrhythm to the double accented note that follows, creating a forward-oriented surge of energy. This approach transforms the double accents from phenomenal ones to structural ones; they now play a substantial role in group and phrase delineation. The energy accumulated in them then dissipates through the following material and rebuilds through the ensuing polyrhythm. After Sørensen has performed a few of these units, their autotelic nature conditions the listener to expect more of the same, locking into the flow of energy that both the unit-as-notated and his dynamics purvey.

[6.6] Aspects of grouping and segmentation are more pronounced in Rebonds B, especially later in the movement. But the groove texture that characterizes the movement's first 65 measures (out of a total of 87) imparts three simultaneous patterns that rarely line up metrically: the accent and ruff patterns on the high-bongo line and the cyclical five-note pattern played on the lower four drums.

(28) The opening four measures evoke a weak sense of 4/4 meter through the high-bongo ruffs that occur regularly at the half measure. The cyclical pattern of the lower drums presents a different issue. While the pattern clearly begins on the tom tom, moving down to the bass drum before cycling down through the low bongo, tumba, and again bass drum, boundaries between iterations of this cycle are audibly unclear (despite being easy to identify in the score). This issue arises because the final bass drum of the cycle is usually the shortest duration of the five attacks, normally only one sixteenth note long, and the cycle-initiating tom tom is given more space following it: the chart in Example 14 shows that the duration of the tom tom attack is the longest of any drum across the first nine cycles. ${ }^{(29)}$ The gap following each tom tom, then, seems a better candidate for segmentation; but this would suggest that the cycle ends with the tom, and does not begin with it as the score suggests. ${ }^{(30)}$ Again, the way this cyclical pattern is performed-both in terms of drum tuning and accent strength - will affect both how grouping boundaries are perceived and how objects are rendered salient and aurally categorized, after Maler. But a more fundamental question arises here: there are also two cyclical processes occurring within the pulsing high bongo. How are these reconciled against the grouping structure of the lower drums? While grouping boundaries for each process can be identified and measured against one another, the performer's reality is that these must be negotiated simultaneously, an idea that will be explored in the next section.

\section{Score Fidelity in Rebonds B}

[7.1] Score-based analysis operates on the assumption that notes on the page will be interpreted in performance, and thus heard by the listener. An analytical reading is essentially a "hearing"; out of time, but audiated nonetheless. ${ }^{(31)}$ Even in performance traditions where interpretive liberty is common, analysis assumes that the notes on the page will be played, albeit perhaps not exactly as written. And while John Cage and other composers have injected elements of indeterminism into 
the fabric of twentieth-century art music - creating space for performer-led decisions on musical structure-Xenakis's percussion literature often features passages in otherwise determinate scores where performers might not interpret the score as written. For Rebonds, this is on top of the liberal approaches to tempo, accent, and pitch described above. What I am referring to here are instances where performers simply leave out material, or perform it completely differently to how it is notated.

[7.2] Many of these instances in Xenakis's music are problematic for performers by virtue of their extreme physical difficulty or non-idiomaticity. In the climactic finale of Persephassa (1969), each of the six percussionists navigate a lengthy tremolo passage across seven instruments; instruments that, by virtue of their size, must be placed far from one another. Partway through this passage, which is in constant accelerando, the individual parts become quasi-impossible to perform as notated, and compromises must be made in live performance. ${ }^{(32)}$ In Psappha (1975), the percussion soloist must, at one point, produce sound on eleven (!) different instruments simultaneously. ${ }^{(33)}$ In Rebonds $B$, the difficulties are slightly less dramatic; the two-stroke ruffs and multiple drums sounding at the opening, the simultaneous pulsing and rolling of woods in the middle, and the movement's final 10 measures, where the woods and skins combine in rhythmic figures that densely incorporate ruffs and rolls, all tug at the fringes of the possible for the performer. I stop short of calling these passages truly impossible-they are not literal impossibilities like the ones Julian Hook identifies in 19th-century music (2011) - but their quasi-impossibility gives performers pause on how to approach playing them. Schick argues that such near-impossible moments often "coincide with a moment of maximum impact in the composition" $(2010,201)$. With that, I now turn to two of these quasi-impossible passages in Rebonds $B$ by characterizing their structural significance in the composition and evaluating the range of approaches to interpreting them, as evinced by the recordings.

[7.3] As described earlier, the opening texture of Rebonds B is polyphonic. The dialogue between the pulsing high bongo and the cyclical pattern of the lower four drums pervades most of the movement, and the two-stroke ruff pattern played on the high bongo characterizes the "rebound" (after the work's title). The ruff pattern remains the sole property of this instrument before being "cut loose" (Schick 2006, 207) midway through the movement, eventually careening across all ten drums and woods. The structural significance of this opening texture, then, is in its provision of the basic musical material for the whole movement. Indeed, no new material emerges until tremolo figures gradually pervade the texture beginning at $\mathrm{m}$. 34. The two-stroke ruff pattern, shown in its recurrence across the opening two measures of the movement in Example 15, is normally played by one hand as a double stroke (a quick, rebounding pattern where, with one arm movement, two strokes occur by virtue of actions made by the performer's wrist and fingers); this enables fluidity and variance in the ruffs' speed. The recordings included with Example 15 reveal how flexible the very performance of the two-stroke ruff is in itself: Kato performs the ruffs very tightly (in percussion terminology this would be called "closed"), almost compressing them into one note (this is done by gripping the stick tightly and firmly pressing into the drumhead), Fischer's ruffs are more "open," and Sietzen's are very "open," to the point of almost sounding like sixty-fourth notes.

[7.4] But double strokes almost immediately become an issue, because the ruff pattern often precedes multiple simultaneous drum attacks. ${ }^{(34)}$ The performer has several options available to them, all described below and four of which are visualized in Example 16. The stickings shown for these options assume the bass drum on the left of the player, and the bongos on the right (a relatively standard setup for right- and left-handed players alike):

1. Option 1: play the ruff as a double stroke with the right hand and play the lower drum with the left, leaving out the bongo note.

2. Option 2: play the ruff as a double stroke with the right hand and play both the bongo and lower drum with the left, holding two sticks or mallets.

3. Option 3: play the ruff as a double stroke with the left hand and move very quickly to reach the lower drum also with the left, freeing the right to play the bongo. ${ }^{(35)}$ 
5. Option 5, not shown in Example 16: superimpose, upside down, an identical pair of bongos above the main bongos so the performer has two playing surfaces to oscillate between. ${ }^{(36)}$

Each of these solutions is imperfect. Option 1 leaves out a note. Options 2 and 5 are excessively awkward because they, in part, dictate that the performer must navigate multiple mallets or superimposed drums for the rest of the movement. And options 3 and 4 compromise the accuracy and musicality of the ruff pattern. In my experience (including in my own performances), the overwhelming majority of interpretations choose option 1 ; thus, for each double-stop that coincides with a ruff, the high bongo attack is abandoned in favor of preserving the integrity of the ruff that preceded it. Of the ten recordings surveyed, eight audibly abandon the bongo note in this way. ${ }^{(37)}$

[7.5] It is evident that performers choose the logistically efficient solution. But what consequences does this decision have on the movement's structure as embodied by its opening? First, option 1 casts into relief the importance of the ruff figure and the cyclical melody on the lower drums. In opting to sacrifice the occasional high bongo note to preserve the musicality of the ruff and the integrity of the cyclical pattern, performers are inherently foregrounding these two features. Second, while the pulsation, ruffs, and cyclical drum patterns may be stratified on paper-with only few points of co-ordination - in performance they are inextricably intertwined. Most performers play the bongo pulses and ruffs with one hand (usually the right hand), and the cyclical pattern on the low drum with the other (left), resulting in what Schick describes as a "gestural polyphony: [where] the right half of the body looks almost immobile while the left half is highly engaged" $(2006,209)$. But whenever a ruff precedes a lone bongo pulse attack, these attacks are usually played with the left hand, meaning the performer is using one hand for the cyclical pattern, the other hand for the ruffs, and both hands for the pulse. Earlier I described this opening texture of Rebonds $B$ as comprising three non-aligned, stratified cyclical processes. It would thus seem appealing to analyze them in this way, investigating their points of temporal coordination and divergence. But what becomes apparent through many of the aforementioned solutions to the ruff problem is that these cyclical patterns are inextricably intertwined in the performer's body; their unification through performer embodiment adds a new dimension to their structural relationship in Rebonds B. ${ }^{(38)}$

[7.6] Woods and skins are combined in a composite texture from $\mathrm{m}$. 74 until the end of the movement in Rebonds B. Concurrent with this timbral blending comes more frequent interaction between tremolo and non-tremolo musical figures, which have hitherto existed apart from one another. The first passage to juxtapose tremolo and non-tremolo patterns occurs in mm. 68-70; an example of Schick's "impossible" passages, this section calls for sustained tremolo in the lower voice and accented, ruff-infused pulses in the upper. This is indeed a moment of "maximum impact" as Schick describes it: two opposing textures of pulse and tremolo are at last intertwined. The reader, armed with this description and an excerpt of the passage shown in Example 17, might surmise that it requires more than two hands/striking implements to perform. Indeed, tremolos and ruffs each normally require two hands, and their simultaneous presence here presents an interpretive challenge.

[7.7] As might be expected, interpretations of this passage tend to vary widely. Due to the density of the passage, the performer must devote one hand to each "voice," but this is insufficient for either voice by virtue of the material they each contain. Only one of the ten recordings consulted executes the passage exactly as written: Ferrière's performance involves two "hacks" to achieve this. First, she uses one of two possible techniques to achieve the constant tremolo on the low woods (shown in Example 18): either by superimposing a second set of equally-tuned woods above the first and oscillating the stick/mallet between their playing surfaces, or by holding two mallets and using a technique known as a "mandolin roll," where both sides of the playing surface are struck - each with one of two mallets or sticks held in the same hand. ${ }^{(39)}$ For the higher voice, Ferrière adds two extra wood blocks that are positioned so she can drag her stick or mallet across the three of them, thus executing the ruff figure-in a slightly roundabout way, with one hand. I describe her interpretation here not to champion it among the others in the study-although it is 
well executed - but rather to contextualize the approaches that are less faithful to the score-asnotated. The solutions Ferrière employs are not secret techniques that only she possesses. The question instead is, why were these techniques not used by the other performers?

[7.8] Seven of the recordings employ an alternating hand-to-hand technique where the pulsed notes are played on-beat and the rolls of the lower voice are evoked through buzz or press-strokes on each off-beat $32^{\text {nd }}$ note. ${ }^{(40)}$ Example 17 re-notates the passage according to this interpretation, along with Klimasara's recording of it. Neither the accented ruffs nor the tremolo are played exactly as written, but short of passing her interpretation off as inaccurate (which it technically is), I propose an alternate reading. This is the only passage in Rebonds $B$ where the ruffs, pulses, and tremolos happen concurrently. And while these elements are diligently stratified in the score, interpretations like Klimasara's blend them as possible nowhere else in the movement. From the perspective of narrative, the blending of ruff, pulse, and tremolo in performance functions as a momentary experiment; such blending is quickly abandoned as tremolo and ruff oppose one another in the movement's finale, amplified by the at-times brutal opposition of wood and skin.

[7.9] These quasi-impossible passages constitute just two of many moments in Rebonds $B$ that present substantial logistical challenges to the performer. The fact that many world-renowned percussionists have addressed these challenges in unique ways (quite often in departure from the score's notation) suggests the notion of difficulty in Xenakis is a multifaceted one. Interviews with Xenakis, as well as third-party recollections of conversations with him, reveal that he was cognizant of the interpretive difficulties his compositions proposed. ${ }^{(41)}$ But at the same time, he seems to have been acutely aware that performers not only required sustained contact with his pieces to eventually surmount these difficulties, but that the very surmounting itself was perhaps a collective, multifaceted process. In his interviews with Bálint András Varga, Xenakis states that: "I do take into account the physical limitations of performers ... but I also take into account the fact that what is limitation today may not be so tomorrow" $(1996,65)$. This quote speaks to a legacy of Xenakis that cannot be documented through a score-led study of his compositions: his œuvre has contributed just as much to the advancement of performance practice as it has to any measure of aesthetic development in 20th-century music. In other words, to speak of a contemporary performance practice on most instruments is, in part, to speak of the performers and performances that have risen to the challenges presented to them by Xenakis. Perhaps nowhere else is this as obvious as in his solo and chamber literature for percussion.

\section{Conclusion}

[8.1] The compositions of Xenakis force their interpreters to engage in a detailed negotiation, one that reveals some aspects of musical structure embedded in the score and generates others through performance. As such, this process of negotiation provides fertile ground for a decentering of the score as analytical text. I have attempted such a decentering here by using ten recorded performances as an entry point to an analysis of Rebonds. My motivations for doing so initially stemmed from my own relationship with the work as a performer, but also my observation of the highly variegated approaches to interpretation of specific passages in this work. I analyzed these recordings with respect to tempo, instrument choice and tuning (pitch), accent interpretation, and grouping. Finally, I surveyed several moments in Rebonds B where a faithful adherence to the score is, while technically possible, rarely undertaken. I rationalized the varied approaches to specific passages in the work and discussed how a pluralistic conception of structure might emerge when collectively assessing these ten recordings.

[8.2] In Rebonds, Xenakis composed a score rife with structural affordances. The way performers engage with these affordances has consequences on structure at both global (work-wide) and local levels. The foregoing discussion of tempo demonstrates this well. The approximate tempo markings in both movements afford a wide latitude of interpretation; some performers chose to exploit this latitude by opting against maintaining a steady tempo throughout their performance. In Rebonds $A$, this led to my observations toward something of a global structure governed by tempo: many performances appear to have followed similar trajectories whereby a slower opening tempo was initially accelerated and ultimately returned to in the movement's dense conclusion. 
Any number of structural rationalizations could be teased from this tempo trajectory; those relating to Sørensen, Schick, and Sietzen were proposed here. Other performers used tempo to highlight areas of "maximum impact," especially in Rebonds B, where dramatic performance fermatas and inflections of rubato were shown to coincide with structurally significant moments in the movement. It could be argued that these moments are significant because of these performance decisions, and not a priori to them.

[8.3] Structural affordances also manifest through matters of pitch choice and accent production. I demonstrated how drum selection and tuning affects pitch contour and registral stratification in Rebonds $A$. These, too, are global aspects of structure-the drum tunings are fixed throughout a performance-but their local-level ramifications were observed through passages such as those shown in Example 11. Here, the performers are agents in determining a stratification that can readily be heard but are also responsible for marking certain musical figures for increased listener consciousness, either through tuning decisions or accent production. Accents, an omnipresent fixture in both Rebonds $A$ and $B$, may seem integral to each movement's structure, but their frequent omission in Rebonds $A$ especially calls this assumption into question. Furthermore, the nature of accent production on a wide variety of drum sizes renders this action inconsistent, even in the most diligent of performances, and diminishes the accent's structural role: no two accents are the same in performance, perhaps they should not be treated as such in analysis. And through drum tuning choices, accents, and dynamics (which are not printed in the score), performers are able to create structure through grouping and phrase in Rebonds $A$, a movement where such notions are not altogether obvious in the score.

[8.4] Finally, my investigation of performers' voluntary infidelity to the markings of the score in Rebonds $B$ shows how aspects of structure or narrativity can be gleaned from these performances. But in order to do this, we must first notice performance decisions as fleeting as the omission of sixteenth notes in a pulse pattern, and second, accept these decisions not as failures to accurately interpret the score, but as products of negotiation. Depending on how performers negotiate the ruffs in the opening passage of Rebonds B, their embodiment of the passage changes, and the listener/viewer's conception of the score-given polyphony is affected as a result. And whether performers tackle m. 69 in Rebonds B as written, or provide their own solution to the passage's difficult aspects, different structural outcomes ensue. Ferrière's "correct" performance keeps the pulse and tremolo distinct, as though they sidle up against one another and go no further. By contrast, Klimasara sonically blends these two musical figures for a fleeting moment before they are once again separated. Taken together, these investigations into performer/score interaction reveal that musical structure is both activated and created by performers. Structure is thus not understood here as a single, summed assemblage of different interpretations of the same score. Nor am I particularly concerned with any one interpretation of Rebonds as generating a particular conception of structure. Indeed, each performance does achieve this. Structure is everywhere we look for it: in the score, in the performer's body, and in the sounds we hear and movements we see. No one of these sites of musical structure exists independently of any other-it is their interrelatedness that gives rise to their meaning.

[8.5] The analyses presented in this study raise several questions. First, how would a consideration of the visual aspect of Rebonds performance contribute to the work's structural fabric? Accents, for example, might be perceived differently if listeners are able to see performers' movements related to accent production. Second, when a number of performances-by world-class percussionists no less-diverge from the score in the omission of notes, the softening of accents, the insertion of dramatic tempo changes, or altering of entire passages, do conventions that arise out of those performance practices become part of the structural fabric of the work? Are these conventions inseparable from the musical "text" of Rebonds? I have attempted to make the case that they indeed are. But whether or not this argument is sufficiently convincing for all readers, I hope that another point may be taken away from the foregoing discussion: that the musical score itself is the medium in which negotiations between its creator, interpreters, and its sound objects take place.

Negotiations that each produce a unique musical text. And negotiations in which the role of creator of a flexible and multidimensional musical structure becomes shared between composer and performer. 
[8.6] One of my percussion teachers in graduate school had previously studied with the dedicatee and premiering performer of Rebonds, Sylvio Gualda. This teacher relayed to me an anecdote (which he had heard from Gualda) from the period when Gualda was preparing for the French premiere of the work. Gualda allegedly told Xenakis: "some passages [in Rebonds] are impossible to play," to which Xenakis casually replied, "I am sure you will do it very well Sylvio" ("Je suis sûr que vous ferez ça très bien, Sylvio"). ${ }^{(42)}$ Regardless of the accuracy and veracity of this anecdote, it seems likely that Xenakis knew Gualda would find a way to perform Rebonds, and would thus undertake his own negotiation-filled, structure-generating journey with the work. And so it has been the way for countless other percussionists since.

Ben Duinker

Faculty of Music, University of Toronto

Edward Johnson Building

80 Queen's Park

Toronto Ontario M5S 2C5

Canada

benjamin.duinker@utoronto.ca

\section{Works Cited}

Benadon, Fernando. 2009. “Time Warps in Early Jazz.” Music Theory Spectrum 31 (1): 1-25. https://doi.org/10.1525/mts.2009.31.1.1.

Benadon, Fernando, and Damián H. Zanette. 2015. “A Corpus Analysis of Rubato in Bach's C Major Prelude, WTC I." Music Performance Research 7: 1-26.

Beyer, Greg. 2005. “All is Number: Golden Section in Xenakis' Rebonds.” Percussive Notes 43 (1): 4856.

Black, Robert. 2010. “Theraps.” In Performing Xenakis, ed. Sharon Kanach, 241-44. Pendragon Press.

Chen, Ying-Hsueh. 2017. "Iannis Xenakis: Rebonds (b and a), played by Ying-Hsueh Chen." YouTube. Accessed December 11, 2020. https://youtu.be/WIN3-VzqdAo.

Chojnacka, Elisabeth. 2010. “The Harpsichord According to Xenakis.” In Performing Xenakis, ed. Sharon Kanach, 71-90. Pendragon Press.

Clarke, Eric. 2004. "Empirical Methods in the Study of Performance." In Empirical Musicology: Aims, Methods, Prospects, ed. Eric Clarke and Nicholas Cook, 77-102. Oxford University Press. https://doi.org/10.1093/acprof:oso/9780195167498.003.0005.

Concours de Genève. 2019. 74e Concours de Genève International Music Competition: Percussion Rules. Accessed December 7, 2020. https://www.concoursgeneve.ch/site/app/webroot/kcfinder/upload/files/re\%CC\%80glement\%20percussion\%202019 eng.pdf.

Cook, Nicholas. 1987. "Structure and Performance Timing in Bach's C-major Prelude (WTC I): An Empirical Study." Music Analysis 6 (3): 257-72. https://doi.org/10.2307/854205.

- 2013. Beyond the Score: Music as Performance. Oxford University Press. https://doi.org/10.1093/acprof:oso/9780199357406.001.0001.

Cooper, Grosvenor, and Leonard Meyer. 1960. The Rhythmic Structure of Music. University of Chicago Press.

De Clercq, Trevor. 2012. "Measuring a Measure: Absolute Time as a Factor for Determining Bar Lengths and Meter in Pop/Rock Music." Music Theory Online 22 (3).

https://doi.org/10.30535/mto.22.3.3. 
De Cock, Tom. 2015. "Rebonds." Living Scores Learn. Accessed December 1, 2020. http://www.livingscores.com/learn/platform/iannisxenakis/compositions/rebonds/.

Duinker, Ben. 2013. “Rebonds: Thoughts on Structure and Performance.” In Xenakis Matters, ed. Sharon Kanach, 219-30. Pendragon Press.

Fraisse, Paul. 1982. "Rhythm and Tempo." In the Psychology of Music, ed. Diana Deutsch, 149-80. Academic Press. https://doi.org/10.1016/B978-0-12-213562-0.50010-3.

France Musique. 2018. “Iannis Xenakis: Rebonds - B (Adélaïde Ferrière).” YouTube. Accessed December 11, 2020. https://youtu.be/TJmCowli8uI.

Gibson, James J. 1966. The Senses Considered as Perceptual Systems. Houghton Mifflin.

Gualda, Sylvio. 2010. “On Psappha and Persephassa.” In Performing Xenakis, ed. Sharon Kanach, 159-66. Pendragon Press.

Guck, Marion. 2006. “Analysis as Interpretation: Interaction, Intentionality, Invention." Music Theory Spectrum 28 (2): 191-209. https://doi.org/10.1525/mts.2006.28.2.191.

Harley, James. 2004. Iannis Xenakis: His Life in Music. Routledge.

Hook, Julian. 2011. “How to Perform Impossible Rhythms.” Music Theory Online 17 (4). https://doi.org/10.30535/mto.17.4.1.

Kanach, Sharon, ed. 2010. Performing Xenakis. Pendragon Press. 2012. Xenakis Matters. Pendragon Press.

Kato, Kuniko. 2015. “REBONDS a.b. - Iannis Xenakis by Kuniko.” YouTube. Accessed December 11, 2020. https://youtu.be/YXNkUgrK4R8.

Krebs, Harald. 1999. Fantasy Pieces: Metrical Dissonance in the Music of Robert Schumann. Oxford University Press. https://doi.org/10.1093/acprof:oso/9780195116236.001.0001.

Lawrence, John Y. 2017. "Hearing Voices in Their Hands: Performing and Perceiving Polyphony." Paper presented at the European Music Analysis Conference (EuroMAC 9), Strasbourg, FR, June 28-July 1.

Leong, Daphne. 2016. "Analysis and Performance: Or wissen, können, kennen." Music Theory Online 22 (2). https://doi.org/10.30535/mto.22.2.6.

2019. Performing Knowledge: Twentieth-Century Music in Analysis and Performance. Oxford University Press. https://doi.org/10.1093/oso/9780190653545.001.0001.

Lerdahl, Fred, and Ray Jackendoff. 1983. A Generative Theory of Tonal Music. MIT Press.

London, Justin. 2012. Hearing in Time: Psychological Aspects of Musical Meter. 2nd ed. Oxford University Press. https://doi.org/10.1093/acprof:oso/9780199744374.001.0001.

Maler, Anabel. 2018. “Hearing Form in Post-Tonal Music.” PhD diss., University of Chicago.

Maranda, Olivier. 2011. "Rebonds et Psappha de Iannis Xenakis : la problématique d'interprétation." DMus diss., Université de Montréal.

Ohriner, Mitchell. 2012. “Grouping Hierarchy and Trajectories of Pacing in Performances of Chopin's Mazurkas." Music Theory Online 18 (1). https://doi.org/10.30535/mto.18.1.6.

2019. "Expressive Timing." In The Oxford Handbook of Critical Concepts in Music Theory, ed. Alexander Rehding and Steven Rings, 369-96. Oxford University Press. https://doi.org/10.1093/oxfordhb/9780190454746.013.33. 
Palmer, Caroline. 1996. "Anatomy of a Performance: Sources of Musical Expression." Music Perception 13 (3): 433-53. https://doi.org/10.2307/40286178.

Parncutt, Richard. 1994. "A Perceptual Model of Pulse Salience and Metrical Accents in Musical Rhythms." Music Perception 11 (4): 409-64. https://doi.org/10.2307/40285633.

Pell, Nathan. 2019. “Tempo as Form.” Performance and Analysis Interest Group Blog. Accessed April 13, 2021. https://smtpaig.wordpress.com/2019/05/31/tempo-as-form/.

Prommel, Peter. 2009. “Tom de Cock KE Prüfung Xenakis Rebonds B.” YouTube. Accessed December 11, 2020. https://www.youtube.com/watch?v=2RImMzSXoRY.

Rosenblum, Sandra. 1994. "The Uses of Rubato in Music, Eighteenth to Twentieth Centuries." Performance Practice Review 7 (1): 33-53. https://doi.org/10.5642/perfpr.199407.01.03.

Schick, Steven. 2006. The Percussionist's Art: Same Bed, Different Dreams. University of Rochester Press. 2010. “X is for Xenakis.” In Performing Xenakis, ed. Sharon Kanach, 171-202. Pendragon Press.

Semjen, Andras, et al. 1998. "Getting Synchronized with the Metronome: Comparisons Between Pulse and Period Correction." Psychological Research 61 (1): 44-55. https://doi.org/10.1007/s004260050012.

Porleiksson, Helgi. 2018. “Xenakis Rebonds B: Preparation, Practice, and Performance." Bachelor's degree project, Kungliga Musikhögskolan, Stockholm.

Tinkel, Brian. 2009. "Rebonds by Iannis Xenakis: Pedagogical Study and Performance Analysis." DMA diss., University of Oklahoma.

Tromp Percussion Eindhoven. 2018. Competition Guide. Accessed December 7, 2020. https://issuu.com/tromppercussion/docs/tr18_competition_guide_issuu.

Varga, Bálint András. 1996. Conversations with Iannis Xenakis. Faber and Faber.

Wavequartet. 2017. “Iannis Xenakis: Rebonds B - Christoph Sietzen at 'Stars of Tomorrow' with Rolanda Villazon." YouTube. Accessed December 11, 2020. https://youtu.be/fx9eT5ddfiY.

\section{Footnotes}

* Abridged versions of this paper were delivered at the 2021 Rocky Mountain Music Scholars Conference (Greeley, CO) and the 2021 Nova Contemporary Music Meeting (Lisbon, PT). I thank the conference attendees and anonymous reviewers for their insightful commentary and questions, Aiyun Huang and Fabrice Marandola for teaching me Rebonds in graduate school, and HansKristian Kjos Sørensen, whose recording of Rebonds served as my introduction to the work and kickstarted my fascination with Iannis Xenakis's music. Score examples are reproduced with the kind authorization of Universal Music Publishing and Editions Salabert.

Return to text

1. These ten recordings were chosen subjectively from the approximately 30 available recordings on Apple Music and Spotify. (Because of the COVID-19 pandemic I had no access to physical recordings.) They were selected to represent gender, nationality, and school of performance tradition. (Many percussionists who are serious about solo performance end up studying at a small handful of institutions in North America and Europe.) Age/generation is also balanced here: performers like Steven Schick, Roland Auzet, and Hans-Kristian Kjos Sørensen were already professionally active when Rebonds was composed, while younger performers like Adélaïde Ferrière and Christoph Sietzen learned the work under the tutelage of this earlier generation (though not necessarily from the older performers included in this study).

Return to text 
2. Testament to this focus on Xenakis's scientific predilections can be found throughout the collected edition Xenakis Matters (Kanach 2012), which assembled papers given at the Xenakis: Arts/Science conference held in Montreal in 2010.

Return to text

3. The difficulty in performing Xenakis's works is central to the collected edition Performing Xenakis (2010). Testimony to this can be seen through double bassist Robert Black's comment about Xenakis's Theraps, for solo bass: "[Theraps] ask[s] that we go beyond what we are physically capable of doing. [It] ask[s] the instrument to do more than it is capable of doing" $(2010,243)$.

Return to text

4. See Kanach (2010, xiii).

Return to text

5. Cook uses the term "affordances" here in the sense that it is described in the work by James J. Gibson (1966).

Return to text

6. In effect, this would ideally read "through sight and sound," but my research on Rebonds has not yet considered the visual aspects of performances. This pursuit would no doubt yield more compelling observations on how performers create structure.

Return to text

7. See Palmer $(1996,434)$.

Return to text

8. Xenakis was born of Greek parentage in Romania in 1922. His pursuit to study engineering in Athens was cut short due to the Greco-Italian war (1940-1941) and the Second World War (of which the Balkan theater eventually subsumed the Greco-Italian war), during which time Xenakis participated in the Greek resistance through a number of left-leaning political organizations. His involvement in these conflicts resulted first in a shrapnel injury that left him blind in one eye and disfigured his face, and then in the right-wing Greek government's persecution of former communist operatives. Xenakis fled Greece in 1947, was sentenced to death in absentia, and would not return to his native country for nearly 30 years. In Paris he worked as an engineering assistant for the architect Le Corbusier. He studied composition with Olivier Messiaen, eventually turning to this pursuit full time. He died in Paris in 2001.

Return to text

9. Harley (2004) explores these in great detail, as do numerous contributions in Kanach (2012). Return to text

10. I have seen over 100 different performers interpret Rebonds and I have performed/recorded it approximately 20 times myself. Three of the preeminent international percussion competitions are worthy of mention here. The Tromp International Percussion Competition (Eindhoven, NL) has included Rebonds as an imposed selection in its first round in each edition since 2010 (see Tromp International Percussion Competition, 2018), the Concours de Genève included it in its last two editions with percussion (see Concours de Genève, 2019), and the ARD International Competition Munich included Rebonds as a selection piece in its 2019 edition, which featured percussion. The $A R D$ Competition has since taken down the repertoire requirements for the 2019 edition, but through an email conversation with the 2019 winner, Kai Strobel (May 20, 2020), I learned of Rebonds's inclusion in this competition.

Return to text

11. Rebonds $A$ and $B$ are frequently performed separately as standalone pieces. Return to text

12. Studies of performance tempo have covered involved repertoire ranging from Johann Sebastian Bach's Well-Tempered Klavier (Cook 1987 and Benadon and Zanette 2015), to Frederic Chopin's Mazurkas (Ohriner 2012), to Louis Armstrong's solos (Benadon 2009), to Kendrick Lamar's rapping 
(Ohriner 2019).

Return to text

13. Tempi for each of these passages was identified using Sonic Visualiser. For m. 1, the average duration between attack points on each quarter note (played on the high bongo) were used to determine tempo. For all subsequent measures, attacks spaced exactly one measure apart in the score were used.

Return to text

14. It is worth noting that, in contrast to many other works for solo percussion, neither Xenakis nor his editors give any instruction on how to set up the instruments. Tinkel (2009), Maranda (2011), and Porleiksson (2018) all reference their personal approaches to instrument set up, noting the ramifications of setup choice on performance practice.

Return to text

15. Though very crude in comparison to Nathan Pell's tempo measurements for performances of sonata-form works (2019), we might consider his "tempo-as-form" analogy to be relevant here. Return to text

16. Measuring performance tempo at more frequent, and regular, mensural intervals might reveal different tempo curves than were procured here. While I acknowledge that such an approach might be considered more objective, my goal here was to closely measure (and compare) tempo in passages that my own analytical work (and intuitions as a performer) has deemed structurally significant.

Return to text

17. Schick's tempo change functions similarly to the performers in Benadon and Zanette's study (2015) who increased their use of rubato at key structural moments.

Return to text

18. Tempi for this opening were obtained using an online tap tempo tool. I tapped along with the first eight measures of each performance and collected the average tempo for this passage based on my taps.

Return to text

19. See Fraisse (1982), Parncutt (1994), and Semjen et al. (1998). De Clercq (2012) offers a method of determining mensural length based on these and other studies, which he applies to the rock/pop repertoire.

Return to text

20. Sandra Rosenblum writes that "during the $19^{\text {th }}$ century tempo rubato became identified primarily with tempo flexibility, mainly the accelerating or slowing down of all the parts together" $(1994,43)$. While Rosenblum does not speak explicitly of a ubiquity of rubato in the nineteenth century, her detailed discussions of its presence in the compositions and performance practices of composers such as Chopin suggests that rubato was indeed a commonly used tool in composition and performance in that century.

Return to text

21. Structural accents might play a role in this work, but the continuous form of each movement calls into question how rigorously structural accents can be interpreted.

Return to text

22. As seen in fragments of Xenakis's sketches, the composer appears to have been more preoccupied with the development of contour and shape than any adherence to metrical organization (see De Cock 2015).

Return to text

23. Brian Tinkel $(2009,27-28)$ points out that Xenakis uses different types of printed accents in Rebonds $A$ and $B$-defining these as "stacatissimo" and "marcato" accents, respectively. In my 
experience, such distinctions between accent types bear little consequence in percussion playing. Return to text

24. Further complicating the timbral palette, some performers opt for different drums in place of the tom toms, including a tumba, especially if they are performing Rebonds $A$ and $B$ on the same instrument setup.

Return to text

25. These were measured first by ear, and then verified with the software Praat. Drum tunings are difficult to precisely ascertain due to the overtones present in the sounds of drum attacks, as well as the fact that drum pitch changes with respect to how hard the skin is struck. The tunings transcribed here, therefore, should be understood to be accurate within a semitone in either direction.

Return to text

26. See Schick 2006, 211.

Return to text

27. See Maler 2018, 55-58.

Return to text

28. Beyer's chart documenting the beat length of each iteration of the five-note pattern $(2005,53)$ reveals the total duration of each iteration to be inconsistent across the movement, suggesting the potential for grouping non-alignment (after Krebs's grouping dissonance, 1999) with the other two patterns played on the high bongo.

Return to text

29. These "durations" mean very little to the ear, as the drum sounds are instant, without any sustain other than reverb decay.

Return to text

30. This idea is raised in the spirit of Lerdahl and Jackendoff's grouping preference rule (GPR) of proximity $(1983,45)$.

Return to text

31. I draw this idea from Marion Guck, who situates analysis as interpretation, the analytical outcome of which constitutes a "hearing" $(2006,193)$.

Return to text

32. Schick admits that, in a recording of Persephassa that he presided over, this section was recorded in multiple takes so that all the information in the score was faithfully executed, resulting in what Schick suggests was "probably the first chance ever to hear exactly what Xenakis actually wrote" (2010, 201).

Return to text

33. Gualda refers to this passage as "treacherously difficult" (2010, 160), but, it should be noted, does not characterize it as impossible. In a similar vein, Chojnacka identifies 15-note chords in the harpsichord part of Oophaa (1989, for harpsichord and percussion), characterizing them as "unplayable" (2010, 87).

Return to text

34. Maranda's exploration of the issue presented in Example 16 focuses on the risks of performing these ruffs inconsistently or with a lack of clarity $(2011,13-15)$.

Return to text

35. Tom de Cock's performance of Rebonds B demonstrates this option. See Prommel (2009), https://youtu.be/2RImMzSXoRY (accessed Dec. 11, 2020).

Return to text 
36. This solution is proposed by Maranda (2011, 14), who writes of other solutions to this issue that that "none of the interpretations of the piece that I have heard present a complete and coherent solution" (13). [Original text: "aucune des versions de la pièce que j'ai entendues n'en présente une proposition complète et cohérente."]

Return to text

37. I located live videos for four of the performers studied here. Though the performances in these videos are not the same as the recordings, it becomes evident that each of the performers seen here have chosen option 1, leaving out the high bongo note. Kato: https://youtu.be/YXNkUgrK4R8 (8:15). Sietzen: https://youtu.be/fx9eT5ddfiY (0:11). Ferrière: https://youtu.be/TJmCowli8uI. Chen: https://youtu.be/WIN3-VzqdAo.

Return to text

38. We could, nevertheless, take this point further, following John Lawrence's integration of performance and perception of polyphony (2017). The three strata identified in the openings of Rebonds B would reside in Lawrence's neutral level (a concept he borrows from Jean Jacques Nattiez). Only through performer and listener engagement with this neutral, objective material, does it represent Lawrence's esthesic (perceptual) definition of polyphony.

Return to text

39. In Ferrière's YouTube performance, a music stand obscures the view of her woodblocks.

Return to text

40. As opposed to the two-stroke ruff, which is played with a fairly loose hand in order for the stick or mallet to rebound freely, the buzz or press stroke involves a tighter grip on the stick/mallet, which in turn causes it to bounce off the playing surface more times, and in quicker succession. Return to text

41. See Varga 1996, where Xenakis states "It [the performance of my works] is very difficult, but sometimes they [the interpreters] succeed" (64).

Return to text

42. This anecdote was verified by Fabrice Marandola in an email message to author, Sep 24, 2020. Return to text

\section{Copyright Statement}

Copyright (C) 2021 by the Society for Music Theory. All rights reserved.

[1] Copyrights for individual items published in Music Theory Online (MTO) are held by their authors. Items appearing in MTO may be saved and stored in electronic or paper form, and may be shared among individuals for purposes of scholarly research or discussion, but may not be republished in any form, electronic or print, without prior, written permission from the author(s), and advance notification of the editors of MTO.

[2] Any redistributed form of items published in $M T O$ must include the following information in a form appropriate to the medium in which the items are to appear:

This item appeared in Music Theory Online in [VOLUME \#, ISSUE \#] on [DAY/MONTH/YEAR]. It was authored by [FULL NAME, EMAIL ADDRESS], with whose written permission it is reprinted here.

[3] Libraries may archive issues of MTO in electronic or paper form for public access so long as each issue is stored in its entirety, and no access fee is charged. Exceptions to these requirements must be approved in writing by the editors of $M T O$, who will act in accordance with the decisions of the Society for Music Theory.

This document and all portions thereof are protected by U.S. and international copyright laws. Material contained herein may be copied and/or distributed for research purposes only. 
